\title{
A Phase 1 dose-ranging study examining the effects of a superabsorbent polymer (CLP) on fluid, sodium and potassium excretion in healthy subjects
}

Lee W Henderson ${ }^{1}$, Howard C Dittrich', Alan Strickland ${ }^{2}$, Thomas M Blok ${ }^{3}$, Richard Newman ${ }^{4}$, Thomas Oliphant ${ }^{5}$ and Detlef Albrecht ${ }^{1 *}$

\begin{abstract}
Background: CLP is an orally administered, non-absorbed, superabsorbent polymer being developed to increase fecal excretion of sodium, potassium and water in patients with heart failure and end-stage renal disease. This study was conducted to evaluate the safety of CLP, and to explore dose-related effects on fecal weight, fecal and urine sodium and potassium excretion, and serum electrolyte concentrations.

Methods: This Phase 1, open-label, dose-escalation study included 25 healthy volunteers, who were administered CLP orally immediately prior to four daily meals for 9 days at doses of 7.5, 15.0, and $25.0 \mathrm{~g} /$ day ( $n=5 / \mathrm{group}$ ). An additional dose group received $15.0 \mathrm{~g} /$ day CLP under fasting conditions, and an untreated cohort $(n=5)$ served as control. Twenty-four-hour fecal and urinary output was collected daily. Samples were weighed, and sodium, potassium, and other ion content in stool and urine were measured for each treatment group. Effects on serum cation concentrations, other standard laboratory values, and adverse events were also determined.

Results: At doses below $25.0 \mathrm{~g} /$ day, CLP was well tolerated, with a low frequency of self-limiting gastrointestinal adverse events. CLP increased fecal weight and fecal sodium and potassium content in a dose-related manner. Concomitant dose-related decreases in urinary sodium and potassium were observed. All serum ion concentrations remained within normal limits.

Conclusions: In this study, oral CLP removed water, sodium and potassium from the body via the gastrointestinal tract in a dose related fashion. CLP could become useful for patients with fluid overload and compromised kidney function in conditions such as congestive heart failure, salt sensitive hypertension, chronic kidney disease and end stage renal disease.
\end{abstract}

Trial registration: NCT01944007

Keywords: Superabsorbent polymer, Dose ranging, Pharmacodynamics, Gastrointestinal fluid removal, Gastrointestinal sodium removal

\footnotetext{
* Correspondence: dalbrecht@sorbent.com

'Sorbent Therapeutics Inc, 710 Lakeway Drive, Suite 290, Sunnyvale, CA 94085, USA

Full list of author information is available at the end of the article
}

\section{Biomed Central}

(c) 2014 Henderson et al.; licensee BioMed Central Ltd. This is an open access article distributed under the terms of the Creative Commons Attribution License (http://creativecommons.org/licenses/by/2.0), which permits unrestricted use, distribution, and reproduction in any medium, provided the original work is properly cited. 


\section{Background}

Fluid overload and sodium retention are central components in the pathophysiology of heart failure, with up to $90 \%$ of hospitalizations in heart failure caused by symptoms and signs of fluid overload [1,2]. There is also growing evidence that hypervolemia per se is independently associated with mortality [3,4]. Concomitant renal dysfunction (chronic kidney disease; CKD) has a strong association with poor outcomes in heart failure patients $[5,6]$. Diuretics are the cornerstone of acute and chronic heart failure therapy, but concerns have been raised about the safety and therapeutic efficacy of high dose diuretic therapy [2,7-9], diuretic resistance in the presence of declining renal function and undesired serum electrolyte effects $[10,11]$. The use of cationic exchange resins for removal of excess sodium and water via the gastrointestinal tract from edematous patients was under considerable study in the late 1940s and early 1950s [12]. These products failed to achieve a significant therapeutic presence, in large measure due to the high dosage required (up to $150 \mathrm{~g} /$ day), problems in taking the large amounts of unpalatable resins, significant abdominal side effects and the advent of loop diuretics. Recently, interest in the use of the gastrointestinal tract to remove fluid and/ or ions using polymers of enhanced efficacy and improved tolerability has been renewed $[13,14]$.

New treatment options for fluid and ion management are a significant medical need [2]. CLP (Cross Linked Polyelectrolyte) is a novel, non-absorbed, superabsorbent polymer that, given orally, absorbs water, sodium and potassium in the gastrointestinal tract with eventual elimination in the feces. The clinical effects of CLP in patients with congestive heart failure and impaired kidney function were recently reported in a Phase 2, doubleblind, placebo-controlled study. Patients administered $15 \mathrm{~g} /$ day CLP lost significantly more weight, had a higher proportion of improvement in New York Heart Association (NYHA) class and showed a trend for improvement in both the six minute walk test and the Kansas City Cardiomyopathy Questionnaire compared to patients receiving placebo [13]. This exploratory Phase 1 study was done before the Phase 2 study and the purpose was to evaluate the safety of CLP, and to explore the doserelated effects on fecal weight, and urine and fecal sodium and potassium excretion.

\section{Methods}

The study was conducted in accordance with International Conference on Harmonisation Good Clinical Practice guidelines and other applicable regulatory requirements and laws. The study protocol was reviewed and approved by the IntegReview Ethical Review Board, Austin, Texas. All subjects provided written informed consent prior to study participation. Trial registration number: NCT01944007.

Healthy volunteers at least 18 years of age considered to be in good general health (no renal, cardiac, hepatic or other major organ dysfunction) and with no prior history of major gastrointestinal surgery, conditions affecting motility, or dyspepsia requiring treatment within the previous 6 months were recruited by the Clinical Pharmacology Research Unit at the Jasper Clinic, Kalamazoo, Michigan.

This Phase 1, open-label, dose-escalation study recruited 25 healthy volunteers who were randomized into five groups ( $n=5$ /group): a) Control (untreated), b) 7.5 g CLP/ day, c) $15.0 \mathrm{~g} \mathrm{CLP} /$ day, d) $15.0 \mathrm{~g} \mathrm{CLP} /$ day (fasted) and e) $25.0 \mathrm{~g} \mathrm{CLP/day.} \mathrm{CLP} \mathrm{was} \mathrm{administered} \mathrm{orally} \mathrm{in} \mathrm{size}$ 00 hydroxypropylmethylcellulose capsules immediately prior to meals (breakfast, lunch, dinner, and snack) in 4 doses divided equally for 9 days, except in the $15.0 \mathrm{~g} /$ day fasted group who received the medication 1 hour prior to meals to evaluate the effects of CLP on an empty stomach. With the exception of administration of study medication, untreated control subjects were exposed to the same conditions and procedures as CLP subjects. All subjects were given identical, standardized meals that were controlled for the amount of calories, level of sodium $(\sim 5000 \mathrm{mg}$ per day $\pm 100 \mathrm{mg}$ ), fiber content (10-15 g per day), fat content, and approximate recommended Dietary Reference Intakes. The study subjects were requested to consume all of their meals. Clinic staff monitored and recorded complete ingestion of the meals served during the study. All fluid intake was recorded.

Subjects were admitted to the research unit on Day -1 (baseline); CLP was administered on Days 1 through 9, and subjects were discharged on Day 10.

Fecal and urine samples for each 24-hour period were collected daily during the treatment period and were weighed and analyzed for sodium, potassium, magnesium, calcium, and phosphorus. Daily samples were pooled for analysis. Analyses of ion content in feces were performed by inductively coupled plasma-optical emission spectroscopy (ICP-OES) at Galbraith Labs Inc. (Knoxville, Tennessee). Urine samples and safety laboratories were analyzed at Bronson Methodist Hospital Laboratory (Kalamazoo, Michigan), using standard clinical automated chemistry techniques.

Safety assessments included daily monitoring of adverse events, vital signs and serum chemistries. Hematology, urinalysis, and 12-lead electrocardiogram (ECG) were measured at baseline and prior to discharge. All blood samples were drawn in the fasting stage before breakfast.

\section{Endpoints}

Endpoints to evaluate the pharmacologic activity of CLP included stool weight, fecal content of sodium, potassium, calcium, magnesium and phosphorus, and urine content 
of sodium, potassium, calcium, magnesium and phosphorus. Safety and tolerability evaluations were based on frequency and severity of adverse events, clinical safety labs and vital signs.

\section{Statistical analysis}

Fecal ion content, fecal weight, urine ion content and serum ion concentration data were summarized for each CLP dose group and the control group using descriptive statistics for an empirically determined steady state period (Days 5-9). The steady state period is illustrated for stool weight for the $15 \mathrm{~g} /$ day fed group in Figure 1. Due to the exploratory nature of the study and the small sample size, no formal confirmatory statistical analysis was performed.

For these descriptive statistical analyses, data collected during the steady-state period were analyzed as the daily average of values measured on Days 5-9. Least squares mean profiles and empirical standard errors for each CLP dose group versus control were estimated via generalized estimating equations in accordance with a 2-group repeated measures analysis of variance (RM-ANOVA) assuming compound symmetry. The least squares means and corresponding 95\% confidence intervals from the RM-ANOVA were then used to depict expected cumulative (Days 5-9) mean values for each pairing of CLP versus control. The incidence of treatment-emergent adverse events for each group was determined. Hematology, serum chemistry and quantitative urinalysis analytes were summarized by treatment group using descriptive statistics; qualitative urinalysis analytes were summarized by treatment group. Descriptive statistics were performed on vital signs data for each treatment group. ECG data were summarized for each treatment group as normal or abnormal; abnormal findings were categorized further with regard to clinical significance.

\section{Results}

Subjects ranged in age from 22 to 68 years (mean, 38.0 years). Approximately half of the subjects (56\%) were male, and dose groups were not balanced with regard to gender: the control group comprised only females, and all but the $15.0 \mathrm{~g} /$ day fed group, which included 2 males and 3 females, had a male to female ratio of $4: 1$. The sample was predominantly Caucasian (84\% of subjects).

\section{Fecal weight}

Mean fecal weight was higher in all CLP groups compared to the control group during study Days 5-9. Mean fecal weight values increased in a dose-related manner and were similar in the fed and fasted $15.0 \mathrm{~g} /$ day CLP groups (Figure 2).

\section{Fecal ion content}

Mean fecal sodium and potassium content were higher in all CLP groups compared to the control group (Figure 3), and increased in a dose-related manner. Mean fecal magnesium and calcium content were similar across treatment groups and fecal phosphorus was lower than the control group at $15.0 \mathrm{~g} /$ day. No differences between fed and fasted state were noted for fecal content of any of the ions.

\section{Urine ion content}

Mean urine sodium and potassium were lower in all CLP groups than the control group, with values in CLP groups showing an inverse relationship to dose (Figure 4).

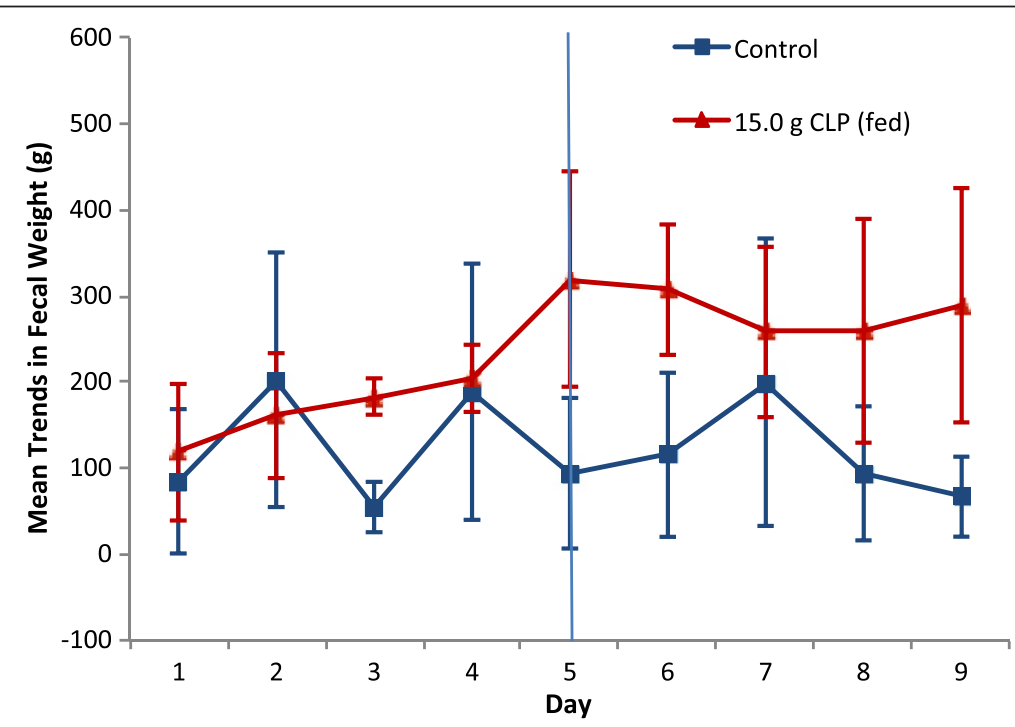

Figure 1 Daily fecal weight following $15.0 \mathrm{~g} /$ day CLP for 9 days under fed conditions. Values are means \pm 95\% confidence intervals. Blue line indicates start of steady state. 


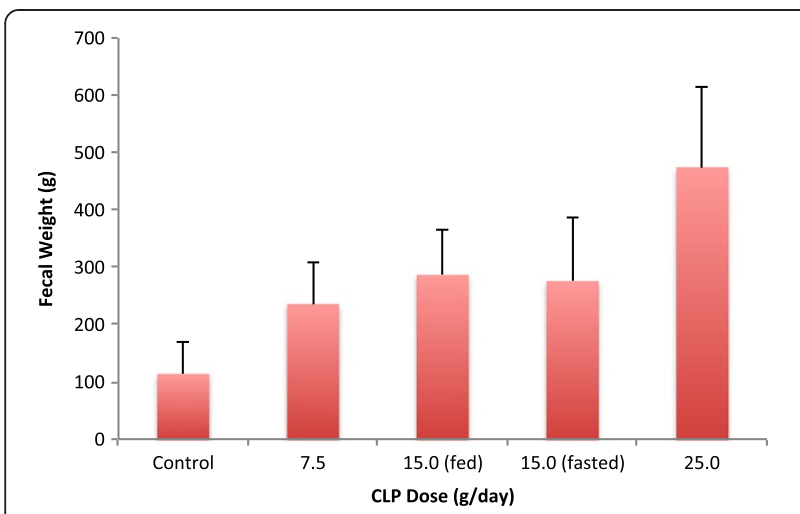

Figure 2 Mean (standard deviation) fecal weight by treatment group. Values are daily averages from Days 5-9, the time period reflective of steady state CLP exposure.

Treatment groups were similar with respect to urine calcium and magnesium, whereas there was an increase in urine phosphorus content at higher doses. There were no noteworthy differences in mean urine cation content values under fed versus fasting conditions.

\section{Serum ion concentrations}

There were no clinically meaningful changes in mean serum ion concentrations during the study. A dose dependent drop in serum potassium resulted in a borderline low serum potassium level in the $25.0 \mathrm{~g} /$ day CLP group (Table 1).

\section{Safety}

Adverse events

No serious adverse events were reported. At doses below 25.0 g/day, CLP was well tolerated. Two subjects in the 25.0 g/day group discontinued CLP dosing on Day 4 due to gastrointestinal adverse events: one due to repeated episodes of moderately severe vomiting, and the other due to abdominal distension, nausea and abdominal pain. Events for both subjects resolved completely without medical treatment prior to discharge on Day 9, five days after termination of dosing. The most frequently reported adverse events were gastrointestinal in nature and appeared to be dose related. However, gastrointestinal adverse events were also reported for 4 of 5 subjects in the control group. The most common gastrointestinal event was nausea. Diarrhea was reported for 1 subject each in the $25.0 \mathrm{~g} /$ day CLP and control groups, and no constipation was reported for any of the subjects on CLP, but it was reported for 2 subjects in the control group. All adverse events were mild to moderate in severity, tended to be transient, and resolved without pharmacologic intervention.

\section{Hematology, clinical chemistries, and other safety assessments}

No clinically significant changes in mean hematology values were observed in any treatment group. With the exception of the serum carbon dioxide concentration $\left(\mathrm{CO}_{2}\right)$, there were no noteworthy changes in mean clinical chemistry values. As shown in Figure 5, serum $\mathrm{CO}_{2}$ decreased as the dose of the acidic CLP polymer increased, and in the $25.0 \mathrm{~g} /$ day CLP group, fell below the



Figure 3 Mean (standard deviation) fecal content of sodium and potassium following CLP treatment and untreated control. Values are daily averages from Days 5-9, the time period reflective of steady state CLP exposure. 


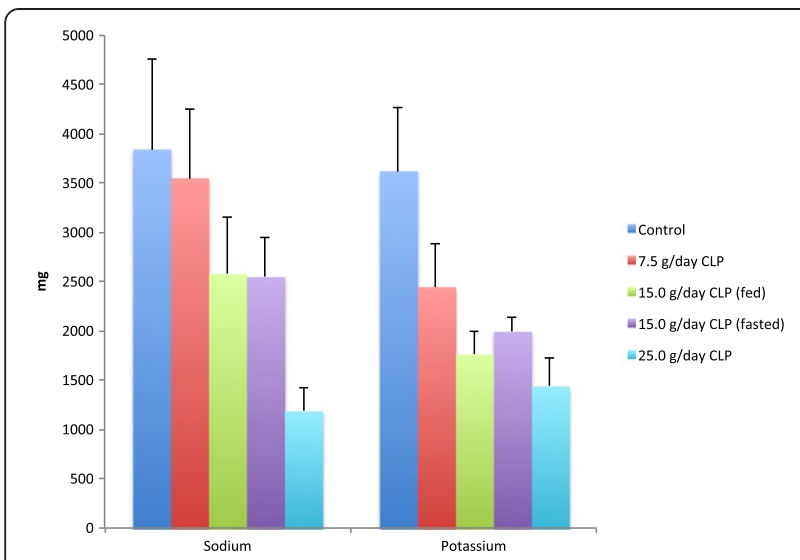

Figure 4 Mean (standard deviation) urine content of sodium and potassium following CLP treatment and untreated control. Values are daily averages from Days 5-9, the time period reflective of steady state CLP exposure.

lower limit of normal on Day 4, and remained decreased until the end of dosing on Day 9. No clinically significant changes in urinalysis were observed, and there were no noteworthy changes in vital signs or ECGs.

\section{Discussion}

This Phase 1 study was conducted to evaluate the tolerability and effects of three different doses of CLP, a novel, non-absorbed superabsorbent polymer, on fecal weight and fecal and urine ion content. No serious adverse events occurred in the 25 subjects studied. At CLP doses below $25.0 \mathrm{~g} /$ day, there was a low incidence of self-resolving, mild adverse events. The $25.0 \mathrm{~g} /$ day dose immediately prior to meals caused more gastrointestinal adverse events, which resulted in 2 subjects discontinuing the study medication. There was no clinically meaningful difference between groups who received $15.0 \mathrm{~g} /$ day CLP under fasting and fed states on any endpoint. Fecal weight, sodium and potassium in the stool were increased relative to control in a doserelated fashion, with a $15.0 \mathrm{~g}$ dose removing approximately $3.0 \mathrm{mEq}$ of sodium and $3.4 \mathrm{mEq}$ of potassium per gram of polymer. Serum potassium and serum sodium concentrations were within the normal range for all subjects, with the $25.0 \mathrm{~g}$ /day CLP group showing a borderline low potassium level. Serum $\mathrm{CO}_{2}$ decreased as the dose of CLP increased; however, only for the $25.0 \mathrm{~g} /$ day CLP group did the serum $\mathrm{CO}_{2}$ fall below the normal range $(23-32 \mathrm{mmol} / \mathrm{L})$.

While there were small changes in fecal phosphorus content, this was considered clinically inconsequential. The reduction in urine sodium and potassium is considered to reflect a normal homeostatic compensation of the kidney for the loss of these cations in the stool [15].

Previous studies with cation exchange resins in the treatment of patients with heart failure and fluid overload demonstrated removal of sodium and potassium via the gastrointestinal route [12]. However, these products failed to achieve a significant therapeutic presence for fluid management, due to the high doses required (up to $150 \mathrm{~g} /$ day), problems in taking the large amounts of unpalatable resins, significant abdominal side effects and the advent of loop diuretics. The much higher cation binding capacity of CLP may offer the opportunity to remove up to $1.0 \mathrm{~g}$ of sodium with a lower dose of drug, improving efficiency and gastrointestinal tolerability. Moreover, the superabsorbent water binding capacity of CLP allows for direct fluid removal via the fecal route without causing diarrhea.

Removal of sodium and fluid in the feces may prove beneficial in patients with kidney failure and fluid overload, as well as in those with heart failure and CKD where the effectiveness of diuretics is limited and diuretic resistance is an increasing problem [2,7-9]. High dietary sodium intake has been implicated in target organ damage in kidney and heart cells via increases in blood pressure and oxidative stress, reduction of arterial elasticity and fibrotic cell remodeling [16]. Dietary sodium restriction is recommended in the management of hypertension, heart failure and CKD [16-18]. Studies have shown the beneficial effects of dietary sodium reduction to lower blood pressure and reduce deaths from heart attack and stroke $[19,20]$. In patients with salt sensitive treatment resistant hypertension, systolic blood pressure reductions of over $20 \mathrm{mmHg}$ have been reported after dietary sodium restriction [21]. Sodium reduction also lowered proteinuria in chronic kidney disease patients [22]. However, dietary sodium

Table 1 Mean serum ion concentrations during study days 5-9 by treatment group

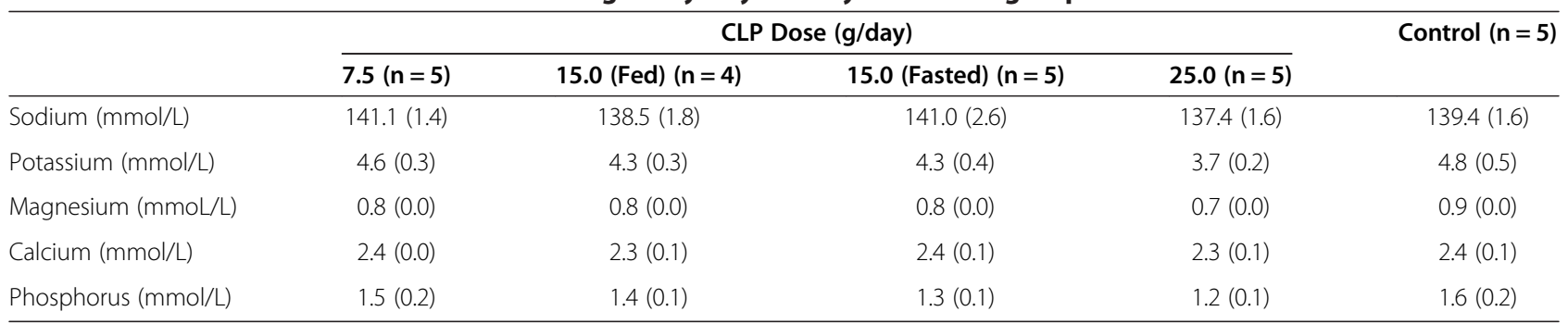

Values are the mean (standard deviation) of daily averages from Days 5-9. 


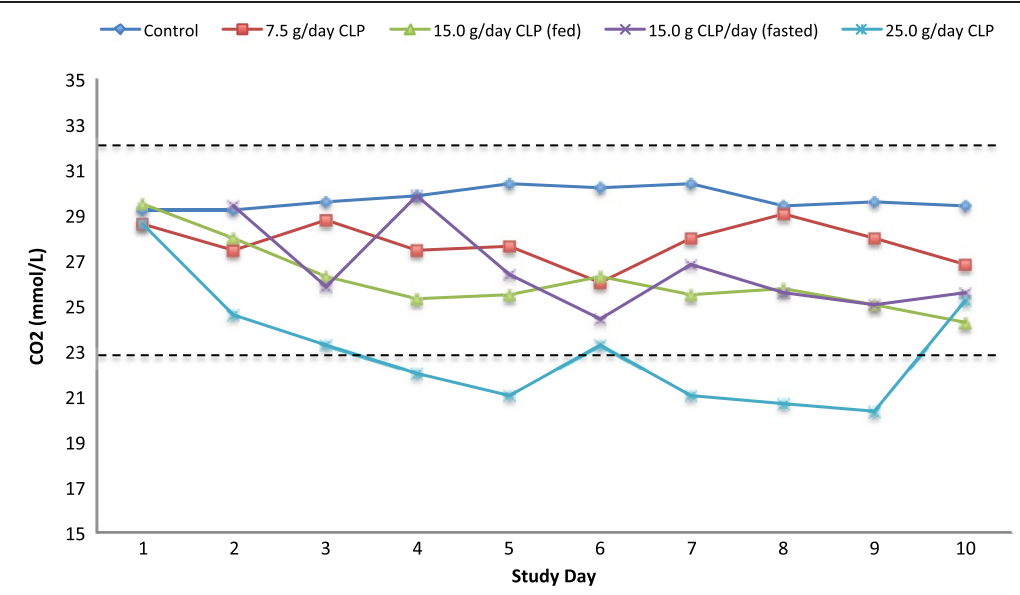

Figure 5 Mean serum carbon dioxide $\left(\mathrm{CO}_{2}\right)$ concentration for each treatment group by study day. Dashed lines represent the normal range $(23-32 \mathrm{mmol} / \mathrm{L})$.

restriction is difficult to achieve and a $15.0 \mathrm{~g} /$ day dose of CLP could remove a clinically meaningful amount of sodium from the systemic circulation [23].

The fecal removal of up to $2.0 \mathrm{~g}$ potassium from the body may have desirable benefits for patients at risk for hyperkalemia such as CKD or heart failure patients, especially patients with a glomerular filtration rate of $\leq 60 \mathrm{~mL} / \mathrm{min}$ who have a higher risk for the occurrence of hyperkalemia [24]. Kayexelate (polystyrene sulfonate), the only approved potassium removing agent, has significant tolerability and safety concerns which would render it inadequate to treat hyperkalemia on a chronic use basis $[25,26]$. Recently, a study with RLY5016 has demonstrated that hyperkalemia may be prevented with a potassium binding oral polymer [14]. However, in a previously reported Phase 2, doubleblind, placebo-controlled study in heart failure patients, no differences were observed between CLP and placebo in serum potassium concentrations. This may have been the result of the concomitant administration of an aldosterone antagonist, which alters serum potassium balance [13].

The main weakness of this study is that the small number of study subjects in each group does not permit formal statistical analysis of differences between groups. A strength of the study is the rigor with which subjects were selected and monitored as inpatients in a metabolic study unit with strict control of total dietary caloric, ion and fluid intake and collection of urine and fecal samples for the duration of the study.

\section{Conclusions}

In this study of healthy volunteers, CLP increased fecal weight and fecal sodium and potassium content in a dose-related manner, and doses below 25.0 g/day were well tolerated, with infrequent, self-limiting gastrointestinal adverse events. CLP may represent a new therapeutic tool for the removal of fluid, sodium and potassium via the gastrointestinal tract in patients with fluid and sodium overload in conditions such as congestive heart failure, salt sensitive hypertension, CKD and end stage renal disease.

\section{Competing interests}

This study was sponsored by Sorbent Therapeutics Inc., Sunnyvale, CA, USA. All authors have completed the Unified Competing Interest form at http:// www.icmje.org/coi_disclosure.pdf (http://www.icmje.org/coi_disclosure.pdf) (available on request from the corresponding author) and declare the following: LWH, HCD and DA are employees of Sorbent Therapeutics Inc., Sunnyvale, CA, USA. DA is a stockholder of Relypsa Inc. AS and RN are paid expert advisors engaged by Sorbent Therapeutics, Inc. to support the design, conduct and analysis of this study. TMB is an employee of the Jasper Clinic's Clinical Research Unit, Kalamazoo, MI, which was engaged by Sorbent Therapeutics, Inc. to conduct this study. TO is an employee of Innovative Analytics, Kalamazoo, MI, which was engaged by Sorbent Therapeutics, Inc. to conduct the data management and statistical analysis for this study. None of the authors received payments for their contributions to the manuscript.

\section{Authors' contributions}

All authors contributed significantly to the study design (LWH, TMB, AS, RN) and conduct $(T M B, T O)$, data analysis $(T O)$ and interpretation (LWH, AS, RN, $H C D, D A)$. They were involved in the drafting and revising of the manuscript and gave full approval for the final version to be published.

\section{Acknowledgments}

For their contributions in the conduct, analysis and reporting of this study, the authors would like to thank Jolene Shorr and Linda De Young, PhD, for editorial assistance, Karen Tindall, BS, and Sandra Mann, BA MT, of Innovative Analytics (Kalamazoo, MI) for data management support, Kay Bentley, BS, of Innovative Analytics (Kalamazoo, MI) for programming support, and finally, Barbara Gullotti, BSN, RN, the Lead Study Nurse, Nabil Ghazal, BS, the Project Manager and Julia Jenkins, RD, the Dietician at Jasper Clinic's Clinical Research Unit (Kalamazoo, MI).

\section{Author details}

'Sorbent Therapeutics Inc, 710 Lakeway Drive, Suite 290, Sunnyvale, CA 94085, USA. ${ }^{2}$ Alan Strickland Consulting, 101 Waterlily, Lake Jackson, TX 77566, USA. ${ }^{3}$ Jasper Clinic's Clinical Research Unit, 526 Jasper Street, Kalamazoo, Ml 49007, USA. ${ }^{4}$ RnD Services, LLC, 635 Bent Creek Ridge, Deerfield, IL 60015, USA. ${ }^{5}$ Innovative Analytics, 161 East Michigan Ave, Kalamazoo, MI 49007, USA.

Received: 4 September 2013 Accepted: 22 January 2014 Published: 25 January 2014 


\section{References}

1. Adams KF Jr, Fonarow GC, Emerman CL, LeJemtel TH, Costanzo MR, Abraham WT, Berkowitz RL, Galvao M, Horton DP, ADHERE Scientific Advisory Committee and Investigators: Characteristics and outcomes of patients hospitalized for heart failure in the United States: rationale, design, and preliminary observations from the first 100,000 cases in the Acute Decompensated Heart Failure National Registry (ADHERE). Am Heart J 2005, 149(2):209-216.

2. Brandimarte F, Mureddu GF, Boccanelli A, Cacciatore G, Brandimarte C, Fedele $F$, Gheorghiade M: Diuretic therapy in heart failure: current controversies and new approaches for fluid removal. J Cardiovasc Med 2010, 11(8):563-570.

3. Drazner MH, Rame JE, Stevenson LW, Dries DL: Prognostic importance of elevated jugular vein pressure and third heart sound in patients with heart failure. N Engl J Med 2001, 345(8):574-581.

4. Costanzo MR, Guglin ME, Saltzberg MT, Jessup ML, Bart BA, Teerlink JR, Jaski BE, Fang JC, Feller ED, Haas GJ, Anderson AS, Schollmeyer MP, Sobotka PA, UNLOAD Trial Investigators: Ultrafiltration versus intravenous diuretics for patients hospitalized for acute decompensated heart failure. J Am Coll Cardiol 2007, 49:675-683. Erratum, J Am Coll Cardiol 2007, 49:1136.

5. Cowie MR, Komaida M, Murray-Thomas T, Underwood J, Ticho B: Prevalence and impact of worsening renal function in patients hospitalized with decompensated heart failure: results of the prospective outcomes study in heart failure (POSH). Eur Heart J 2006, 27:1216-1222.

6. Heywood JT, Fonarow GC, Costanzo MR, Mathur VS, Wigneswaran JR, Wynne J: High prevalence of renal dysfunction and its impact on outcome in 118,465 patients hospitalized with acute decompensated heart failure: a report from the ADHERE database. J Card Fail 2007, 13(6):422-430

7. Ahmed A, Husain A, Love TE, Gambassi G, Dell'Italia L, Francis GS, Gheorghiade M, Allman RM, Meleth S, Bourge RC: Heart failure, chronic diuretic use, and increase in mortality and hospitalization: an observational study using propensity score methods. Eur Heart J 2006 27(12):1431-1439.

8. Domanski M, Tian X, Haigney M, Pitt B: Diuretic use, progressive heart failure, and death in patients in the DIG study. J Card Fail 2006, 12(5):327-332

9. Eshaghian S, Horwich TB, Fonarow GC: Relation of loop diuretic dose to mortality in advanced heart failure. Am J Cardiol 2006, 97(12):1759-1764.

10. Cotter G, Dittrich HC, Weatherley BD, Bloomfield DM, O'Connor CM, Metra M, Massie BM, Protect Steering Committee, Investigators, and Coordinators: The PROTECT pilot study: a randomized, placebo-controlled, dose-finding study of the adenosine $\mathrm{A} 1$ receptor antagonist rolofylline in patients with acute heart failure and renal impairment. J Card Fail 2008, 14(8):631-640. Epub 2008 Sep 14

11. Stanton BA, Kaissling B: Adaptation of distal tubule and collecting duct to increased Na delivery. II. Na + and K + transport. Am J Physiol 1988, 255:F1269-F1275.

12. Dock W, Frank NR: Cation exchangers: their use and hazards as aids in managing edema. Am Heart J 1950, 40:638-645.

13. Costanzo MR, Heywood JT, Massie BM, Iwashita J, Henderson L, Mamatsashvilli M, Sisakian $H$, Hayrapetyan $H$, Sager P, van Veldhuisen DJ, Albrecht D: A double-blind, randomized, parallel, placebo-controlled study examining the effect of cross-linked polyelectrolyte in heart failure patients with chronic kidney disease. Eur J Heart Fail 2012, 14(8):922-930.

14. Pitt B, Anker SD, Bushinsky DA, Kitzman DW, Zannad F, Huang I-Z on behalf of the PEARL-HF investigators: Evaluation of the efficacy and safety of RLY5016, a polymeric potassium binder, in a double-blind, placebo-controlled study in patients with chronic heart failure (the PEARL-HF) trial. Eur Heart J 2011, 32(7):820-828.

15. Linz D, Wirth K, Linz W, Heuer HOO, Frick W, Hofmeister A, Heinelt U, Arndt $\mathrm{P}$, Schwahn U, Boehm M, Ruetten H: Antihypertensive and laxative effects by pharmacological inhibition of sodium-proton-exchanger subtype 3-mediated sodium absorption in the gut. Hypertension 2012, 60:1560-1567.

16. Appel LJ, Frohlich ED, Hall JE, Pearson TA, Sacco RL, Seals DR, Sacks FM, Smith SC, Vafiadis DK, Van Horn LV: The importance of population-wide sodium reduction as a means to prevent cardiovascular disease and stroke. Circulation 2011, 123:1138-1143.

17. Whelton PK, Appel $\amalg$, Sacco RL, Anderson CAM, Antman EM, Campbell N, Dunbar SB, Frohlich ED, Hall JE, Jessup M, Labarthe DR, MacGregor DA
Sacks FM, Stamler J, Vafiadis DK, Van Horn LV: Sodium, blood pressure, and cardiovascular disease: further evidence supporting the American Heart Association Sodium Reduction Recommendations. Circulation 2012. 10.1161/ClR.0b013e318279acbf.

18. Hunt SA, Abraham WT, Chin MH, Feldman AM, Francis GS, Ganiats TG, Jessup M, Konstam MA, Mancini DM, Michl K, Oates JA, Rahko PS, Silver MA, Stevenson LW, Yancy CW: 2009 focused update incorporated into the ACC/AHA 2005 Guidelines for the Diagnosis and Management of Heart Failure in Adults: a report of the American College of Cardiology Foundation/American Heart Association Task Force on Practice Guidelines: developed in collaboration with the International Society for Heart and Lung Transplantation. Circulation 2009, 119(14):e391-e479.

19. Sacks FM, Svetkey JP, Vollmer WM, Appel LJ, Bray GA, Harsha D, Obarzanek E, Conlin PR, Miller ER, Simons-Morton DG, Karanja N, Lin PH: Effects on blood pressure of reduced dietary sodium and the Dietary Approaches to Stop Hypertension (DASH) diet. DASH-Sodium Collaborative Research Group. N Engl J Med 2001, 334(1):3-10.

20. Cook NR, Cutler JA, Obarzanek E, Buring JE, Rexrode KM, Kumanyika SK, Appel $L J$, Whelton PK: Long term effects of dietary sodium reduction on cardiovascular disease outcomes: observational follow-up of the Trials of Hypertension Prevention (TOHP). BMJ 2007, 334:885-888.

21. Pimenta E, Gaddam KK, Oparil S, Aban I, Husain S, Dell'Italia LJ, Calhoun DA: Effects of dietary sodium reduction on blood pressure in subjects with resistant hypertension: results from a randomized trial. Hypertension 2009, 54:475-481

22. Slagman MCJ, Waanders F. Hemmelder MH, Woittiez AJ, Janssen WMT, Lambers Heerspink HJ, Navis G, Laverman GD: Moderate dietary sodium restriction added to angiotensin converting enzyme inhibition compared with dual blockade in lowering proteinuria and blood pressure: randomized controlled trial. BMJ 2011, 343:d4366. 10.1136/bmj.d4366.

23. Centers for Disease Control and Prevention: Usual sodium intakes compared with current dietary guidelines - United States, 2005-2008. MMWR 2011, 60:1413-1417.

24. Pitt B, Bakris G, Ruilope LM, DiCarlo L, Mukherjee R, EPHESUS Investigators: Serum potassium and clinical outcomes in the Eplerenone Post-Acute Myocardial Infarction Heart Failure Efficacy and Survival Study (EPHESUS). Circulation 2008, 118(16):1643-1650.

25. Sterns RH, Rojas M, Bernstein P, Chennupati S: Ion-exchange resins for treatment of hyperkalemia: are they safe and effective? J Am Soc Nephrol 2010, 21:733-735.

26. Watson M, Abbott KC, Yuan CM: Damned if you do, damned if you don't: potassium binding resins in hyperkalemia. Clin J Am Soc Nephrol 2010, 5:1723-1726.

doi:10.1186/2050-6511-15-2

Cite this article as: Henderson et al: A Phase 1 dose-ranging study examining the effects of a superabsorbent polymer (CLP) on fluid, sodium and potassium excretion in healthy subjects. BMC Pharmacology and Toxicology 2014 15:2.

\section{Submit your next manuscript to BioMed Central and take full advantage of:}

- Convenient online submission

- Thorough peer review

- No space constraints or color figure charges

- Immediate publication on acceptance

- Inclusion in PubMed, CAS, Scopus and Google Scholar

- Research which is freely available for redistribution 